\title{
Identification of general acid catalyst for the ATPase activity of Lynch syndrome-related MutL homologs
}

\author{
Kenji Fukui*, Yuki Fujii, and Takato Yano* \\ Department of Biochemistry, Faculty of Medicine, Osaka Medical and Pharmaceutical University, \\ Takatsuki, Osaka; Graduate School of Science, Osaka City University, Sumiyoshi-ku, Osaka, Japan \\ *Correspondence should be addressed to: takato.yano@ompu.ac.jp (TY) and kenji.fukui@ompu.ac.jp

\begin{abstract}
Mutations of mismatch repair MutL homologs are causative of a hereditary cancer, Lynch syndrome. Investigation of MutL facilitates genetic diagnoses essential for cancer risk managements and therapies. We characterized MutL homologs from human and a hyperthermophile, Aquifex aeolicus, (aqMutL) to reveal the catalytic mechanism for the ATPase activity. Although existence of a general acid catalyst had not been conceived in the mechanism, analysis of the $\mathrm{pH}$ dependence of the aqMutL ATPase activity revealed that the reaction is accelerated by general acid-base catalysis. Analyses of mutant aqMutLs showed that Lys79 is the general acid, and the corresponding residues were confirmed to be critical for activities of human homologs, on the basis of which a catalytic mechanism for MutL ATPase is proposed. These and other results described here would contribute to evaluating the pathogenicity of Lynch syndrome-associated missense mutations.
\end{abstract}

Key words: Lynch syndrome, MutL, MLH1, PMS2, ATPase, general acid-base catalysis 
3 DNA mismatch repair (MMR) is a highly conserved DNA repair system, which corrects mismatched bases that are generated by DNA replication errors, recombination between nonidentical sequences, and other biological processes (1-5). MutS homologs initiate MMR by recognizing mismatched bases and subsequently recruit MutL homologs $(5,6)$. In the majority of organisms excluding Escherichia coli and other $\gamma$-proteobacteria, MutL homologs have an endonuclease activity to incise the newly-synthesized, i.e. error-containing, strand of the mismatched DNA duplex (7-9). The mismatched base on the incised strand is removed by exonucleases and the resulting gapped region is filled by DNA replication polymerases.

Since MMR significantly contributes to the genome integrity, mutations and epigenetic silencing of the genes encoding human MutS and MutL homologs sometimes cause Lynch syndrome that is one of the most major hereditary cancers (10-12). Therefore, genetic diagnosis of MMR genes is attracting a great attention in the view of cancer risk management.

Genetic diagnosis of MMR genes is also critical for selection of particular cancer therapies. The MMR pathway participates in induction of apoptosis that is caused by alkylating and crosslinking agents (13). Therefore, MMR-deficient cancer cells are resistant against anticancer drugs such as $N$-methyl- $N$ '-nitro- $N$-nitrosoguanidine and cisplatin (14-17). In addition, it was recently found that MMR-deficient solid tumors are extremely sensitive to immune checkpoint blockade with antibodies to programmed death receptor-1 $(18,19)$. This is because the MMRdeficient cancer cells contain high numbers of somatic mutations and develop a large number of immunogenic neoantigens that are targeted by the immunotherapeutic response $(19,20)$. Thus, genetic diagnosis of MMR genes can be utilized to predict responses of tumors to these anticancer therapeutics and help planning the therapy strategies. 
1 In the past decade, the development of next-generation sequencing technologies enabled

2 identification of numerous mutations of the MMR genes from Lynch syndrome-suspected

3 patients. However, a large amount of those mutations are so-called variants of uncertain

4 significance (VUSs), and it is difficult to determine whether the mutations are pathogenic or

5 benign (21). Presence of VUSs prevents the rapid and accurate genetic diagnosis of MMR genes.

6 Abundance of VUSs in MMR genes is due to the lack of understanding on the function of the

$7 \quad$ MMR proteins at the amino acid residue level. Identification of functionally-important amino acid

8 residues in the MMR proteins is an urgent task to deal with MMR-associated cancers.

9 MutL homologs belong to the GHKL ATPase/kinase superfamily that includes DNA gyrase B 10 subunit (GyrB), ㅍsp90, bacterial histidine kinase, and mitochondrial serine kinase, in addition to

11 MutL (22-24). The GHKL superfamily proteins generally consist of the N-terminal ATPase and

12 C-terminal dimerization domains. The N-terminal domain (NTD) contains a motif comprising

13 four highly conserved amino acid sequences, the Bergerat ATP-binding fold (Fig. 1) (24). ATP

14 binding and hydrolysis at the Bergerat ATP-binding fold induce large conformational changes,

15 which are essential for molecular function of the GHKL superfamily proteins. 
2 Figure 1. Amino acid sequence alignment of MutL homologs. The amino acid sequences of the

3 ATPase domains of aqMutL, E. coli MutL, human MLH1, and human PMS2 were aligned by

4 CLUSTALW (25) and visualized using the ESPript3 program (26). Regions corresponding to

residues $163-255$ of aqMutL are omitted for simplification. Pink and Blue asterisks indicate Lynch

syndrome-associated mutations clinically found in the human PMS2 and $M L H 1$ genes, respectively.

Red asterisks indicate the residues of aqMutL that were mutagenized in this study. Black bars under

the sequences indicate the Bergerat ATP-binding fold.

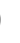

Bacterial MutL endonucleases are homodimeric, whereas eukaryotic counterparts are heterodimeric. Human MutL $\alpha$ is comprised of MutL homolog 1 (MLH1) and postmeiotic segregation increased 2 (PMS2) and is receiving increased clinical attention because a significant number of Lynch syndrome-associated mutations are found in the genes encoding MLH1 and PMS2. Although MLH1 and PMS2 show significant amino acid sequence similarity to each other, only PMS2 contains the metal-binding motif that is responsible for the endonuclease activity and is conserved in MutL homologs from a wide range of organisms including most of bacteria. The

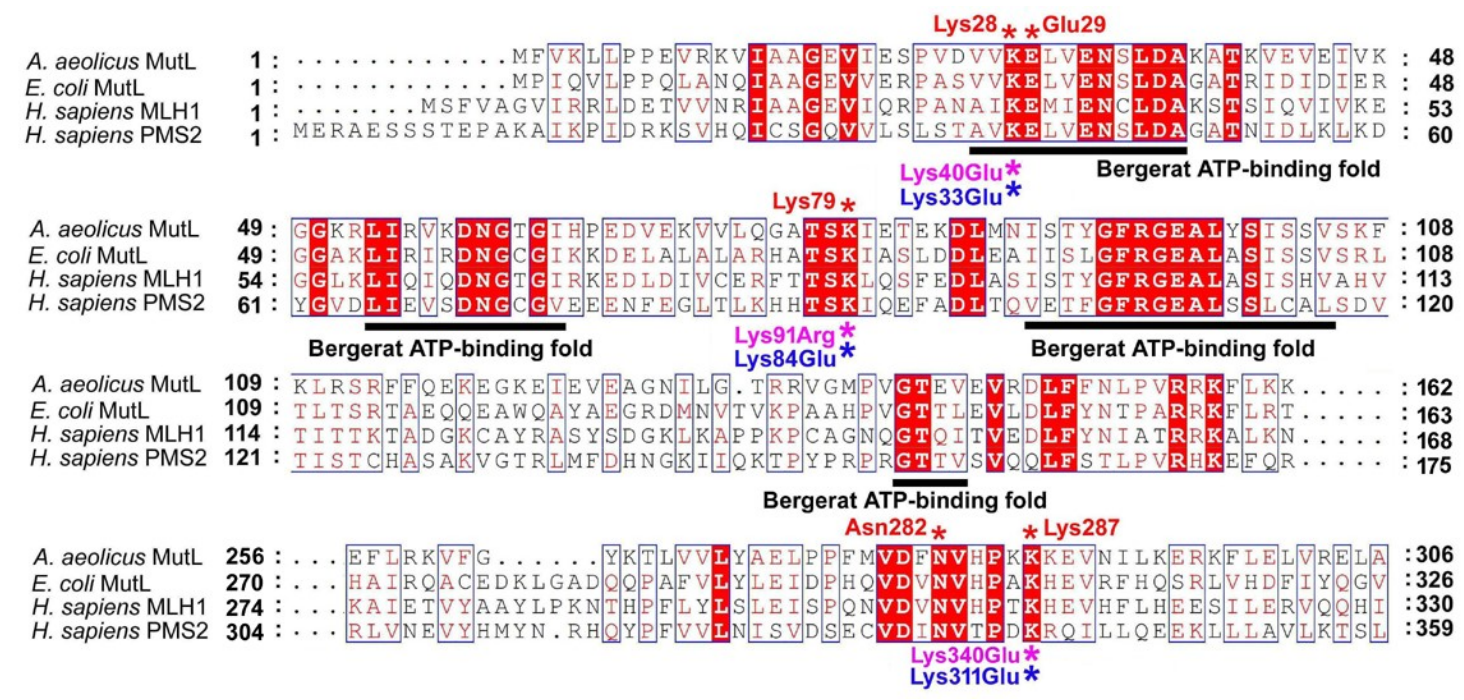


1 endonuclease activity of the MutL C-terminal domain is thought to be regulated by the ATP

2 binding- and hydrolysis-induced conformational changes (27-29), and the ATPase activity of

3 MutL proteins has been shown to be critical for in vivo MMR activity $(30,31)$.

The catalytic mechanism for the ATPase activity of MutL proteins has been learned from structural and functional analyses on E. coli MutL (23), eukaryotic MLH1 (32), and PMS2 (33). In the crystal structure of the E. coli MutL NTD complexed with an ATP analog (23), Glu29 coordinates a water molecule that is located at a position suitable to attack the $\gamma$-phosphoryl group of the substrate. Replacement of Glu29 by an alanine resulted in a complete loss of the activity (23). Glu34 of human MLH1 and Glu41 of human PMS2, corresponding to Glu29 of E. coli MutL, have also been characterized to be essential for the ATPase activity (32). On the basis of these results, Glu29 of E. coli MutL is thought to be the general base to activate the nucleophilic water. In addition, it was demonstrated that the K307A mutation in E. coli MutL resulted in a 20 -fold decrease in the ATPase activity (23). Since Lys307 is located near the $\gamma$-phosphoryl group of the substrate, it has been thought that Lys307 also participates in the catalysis. However, the catalytic mechanism for the ATPase activity of MutL remains to be elucidated. Previously, crystal structures of the NTDs of E. coli MutL (23,34), Aquifex aeolicus MutL (aqMutL) (35,36), human PMS2 (33), human MLH1 (37), and yeast PMS1 (a counterpart of human PMS2) (38) were solved. Although the tertiary structures of these proteins are highly similar to each other, several differences are found in details of their structures. The largest difference is found in the linkage between ATP binding and dimerization of the domains. The binding of ATP analogs to the E. coli MutL and human MLH1 NTDs induces the transformation of five unstructured loops into ordered structures that serve as the dimerization interface. In contrast, in the human PMS2 and aqMutL NTDs, binding of ATP analogs does not induce the transformation of the unstructured loop regions; hence, the ATP analog-bound forms of these 
1 proteins are monomeric. Thus, aqMutL exhibits similarity to human PMS2 and is thought to be

2 suitable as a model molecule to study the molecular mechanism for the ATPase activity of human

3 PMS2 (36).

A. aeolicus is a hyperthermophilic eubacterium that grows at temperatures over $90^{\circ} \mathrm{C}(39)$. aqMutL and other proteins from this bacterium are extremely stable against temperature and $\mathrm{pH}$ changes and, therefore, suitable for physicochemical characterizations. In this study, we examined the $\mathrm{pH}$ dependence of the aqMutL ATPase activity, which led to identification of the catalytically important lysine residues. One of the lysine residues was found to be the general acid in the enzymatic reaction. It was confirmed that the corresponding lysine residues are also critical for the in vitro ATPase activities of human MutL homologs and the in vivo MMR activity in the eubacterium Thermus thermophilus. Based on these results, we propose a model for the catalytic mechanism of the MutL ATPase activity.

\section{Results and Discussion}

pH dependence of the aqMutL ATPase activity.

Generally, plots of reaction rates of an enzyme against $\mathrm{pH}$ reflect ionization states of amino acid residues that are directly involved in the catalysis. Although proteins from human and other mesophilic organisms are generally not tolerant against extreme pHs, it has been known that proteins from thermophilic microorganisms are highly stable under a wide range of $\mathrm{pH}$ conditions $(40,41)$. Therefore, we used aqMutL as a model molecule to study the catalytic mechanism of the MutL ATPase activity. Prior to examining the $\mathrm{pH}$ dependence of the aqMutL ATPase activity, we tested the $\mathrm{pH}$ stability of the full-length aqMutL. aqMutL was incubated at given $\mathrm{pHs}$ for 3 
$1 \mathrm{~h}$ at $60^{\circ} \mathrm{C}$, and the circular dichroism (CD) spectra were measured (Fig. S1). The negative peak

2 values at $222 \mathrm{~nm}$ were constant over a $\mathrm{pH}$ range from 3.5 to 10.7 (Fig. 2A), indicating that aqMutL

3 was stable under these $\mathrm{pH}$ conditions.

4

5

6

7 Supplementary Figure S1. Far-UV CD spectra of aqMutL under various pH conditions. aqMutL was

8 incubated in a pH range $3.5-10.7$ for $3 \mathrm{~h}$ at $60^{\circ} \mathrm{C}$, and the $\mathrm{CD}$ spectra were measured. Each spectrum

9 was generated by accumulating wavelength-scan data 10 times.
$\mathrm{pH} 4.5$

pH 5.0

$\mathrm{pH} 5.5$

$\mathrm{pH} 6.0$

pH 6.5

pH 7.0

pH 7.5

pH 8.0

$\mathrm{pH} 8.5$

pH 8.8

$\mathrm{pH} 9.2$

pH 9.7

pH 10.2

pH 10.7 

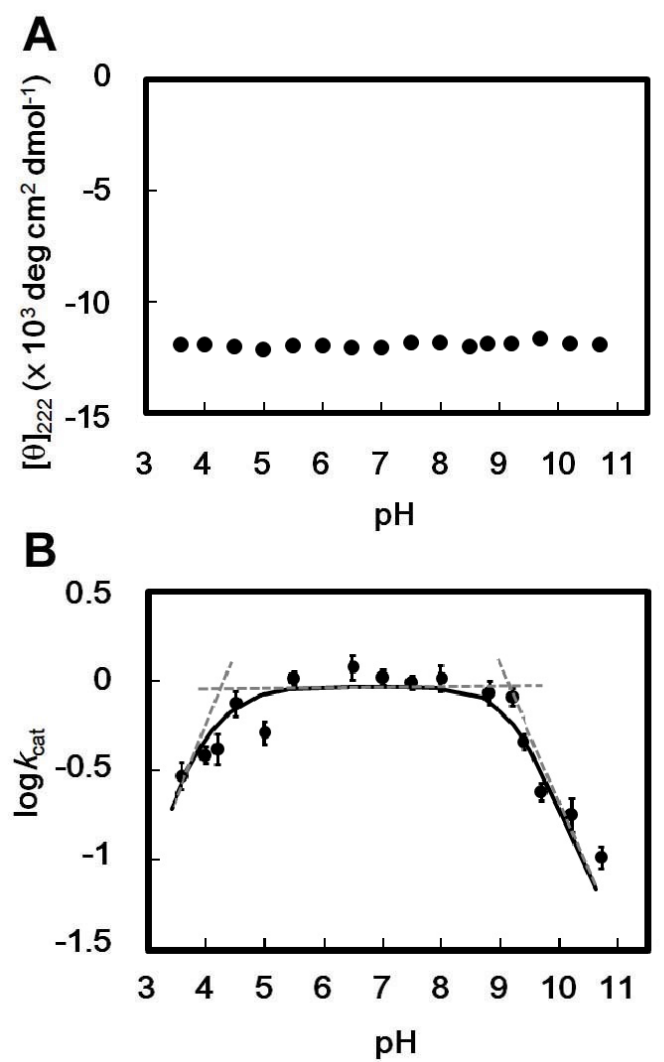

1

2 Figure 2. Effects of $\mathrm{pH}$ on the stability and ATPase activity of aqMutL. (A) aqMutL was incubated

3 in a $\mathrm{pH}$ range $3.5-10.7$ for $16 \mathrm{~h}$, and the $\mathrm{CD}$ spectra were measured. The residue molar ellipticity

values at $222 \mathrm{~nm}$ were plotted against $\mathrm{pH}$.

(B) The ATPase activity of aqMutL was measured in the same $\mathrm{pH}$ range, and the $\log k_{\text {cat }}$ values were plotted against $\mathrm{pH} . \quad k_{\text {cat }}$ values are turnover numbers per minute. Experiments were repeated three times, and bars indicate the standard deviations. A theoretical line derived from the scheme described in the method section is shown as a solid line. Broken lines are drawn to visually indicate the two $\mathrm{p} K_{\mathrm{a}}$ values, 4.1 and 9.4 , obtained by the analysis.

The ATPase activity of aqMutL was measured by detecting the release of the product phosphate using a colorimetric assay. The assay was performed at various ATP concentrations in a $\mathrm{pH}$ range from 3.5 to 10.7 , and each $k_{\text {cat }}$ value was determined by fitting the standard Michaelis- 
1 Menten equation to the data. The $k_{\text {cat }}$ versus $\mathrm{pH}$ profile was bell-shaped with maximal $k_{\text {cat }}$ values

2 at $\mathrm{pH} 5-8$ (Fig. 2B). The profile is best explained by that the enzyme, or, to be more precise, the

3 enzyme-substrate complex, has two catalytically essential dissociable groups; one with a $\mathrm{p} K_{\mathrm{a}}$ of

44.1 has to be deprotonated and the other with a $\mathrm{p} K_{\mathrm{a}}$ of 9.4 protonated for the catalysis to proceed.

5 It is known that free ATP exhibits two $\mathrm{p} K_{\mathrm{a}}$ values, around 4.3 and 6.5 , which reflect dissociation

6 of protons from $N_{1}$ of the adenine ring and the $\gamma$-phosphoryl group, respectively. Previous

7 studies, however, indicated that Glu29 of E. coli MutL, corresponding to Glu29 of aqMutL, serves

8 as the general base in the catalysis (23). Therefore, we postulated that the bel-shaped profile of

9 the $\mathrm{pH}$ dependence reflects the protonation states of the enzyme aqMutL. The existence of a general acid with an alkaline $\mathrm{p} K_{\mathrm{a}}$ has not been postulated in the MutL reaction, and, thus, we aimed to identify an amino acid residue functioning as the general acid catalyst.

Lys28 is important for the protein stability and involved in the ATPase activity, but not the general acid catalyst.

In the crystal structure of the ATP analog-bound form of the aqMutL NTD (36), Glu29 of the Bergerat ATP-binding fold (Fig. 1) forms a hydrogen bond with a water molecule that is located at an optimal position to attack the $\gamma$-phosphoryl group of ATP (Fig. 3A). This is consistent with the notion that Glu29 functions as the general base to activate the nucleophilic water. Interestingly, the $\varepsilon$-amino group of Lys 28 interacts with the carboxy group of Glu29. Lys28 is included in the Bergerat ATP-binding fold and conserved in all MutL homologs (Fig 1). To the best of our knowledge, no previous report has studied the role of this lysine residue. In addition, substitution of a glutamate for Lys40 in human PMS2 or Lys33 in human MLH1, which 
bioRxiv preprint doi: https://doi org/10.1101/2021 07.09.451751 this version posted July 10, 2021. The copyright holder for this preprint (which was not certified by peer review) is the author/funder, who has granted bioRxiv a license to display the preprint in perpetuity. It is made available under aCC-BY 4.0 International license. classified as a VUS (Fig. 1).

3

4

5

6

7

8
A

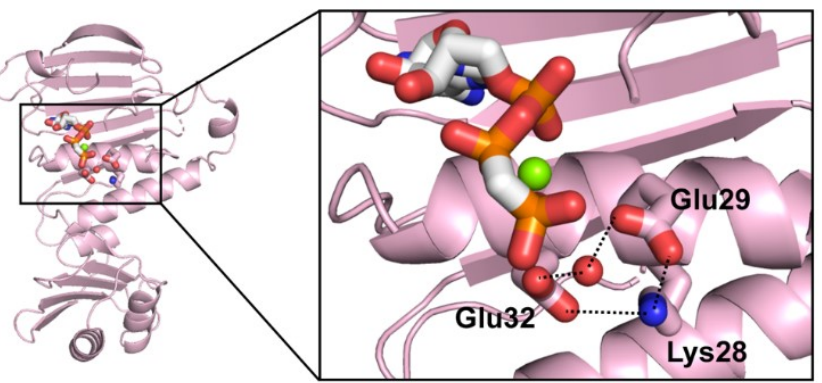

B

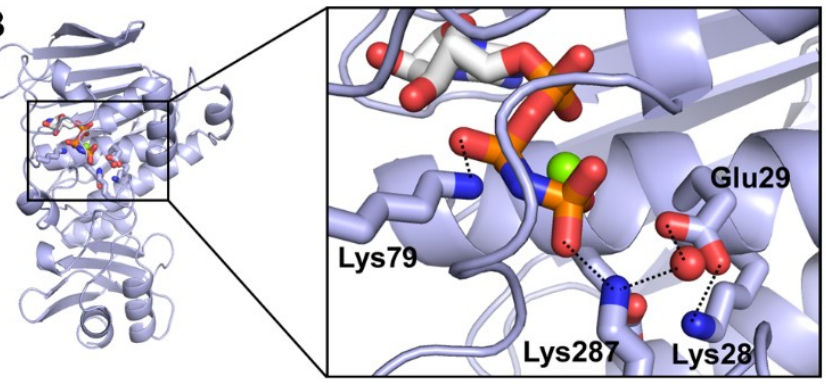

Figure 3. ATP-binding site of the aqMutL NTD. (A) The crystal structure of the aqMutL NTD complexed with the ATP analog AMPPCP (PDB ID: 6LZJ). (B) A model structure of an ATP analog-bound state of the aqMutL NTD was generated by the SWISS-MODEL homology-modeling pipeline (42) using the crystal structure of the AMPPNP-bound E. coli MutL NTD (23) as a template structure. Magnesium ion and the nucleophilic water are shown as green and red spheres, respectively. The ATP analogs and the side chains of the interacting residues are shown in stick models. In the model structure, Lys79 and Lys 287 interact with the $\beta$ - and $\gamma$-phosphoryl groups of the ATP analog, respectively. 
We created the K28E aqMutL and examined its physicochemical properties and ATPase

2 activity. The CD spectrum of the K28E aqMutL was exactly the same as that of the wildtype

3 aqMutL (Fig. 4A), indicating that the mutation does not influence the overall structure of the

4 protein. However, the $\mathrm{CD}$ intensity of the $\mathrm{K} 28 \mathrm{E}$ aqMutL started to decrease at lower

5 temperatures and lower concentrations of a denaturing agent than the wildtype aqMutL (Fig. 4B

6 and C). These results suggest that the K28E mutation destabilizes the structure of aqMutL.

$7 \quad$ The ATPase activity of the K28E aqMutL was measured, and the kinetic parameters were

8 determined (Fig. 5A and Table 1). Although the $k_{\text {cat }}$ value was decreased by 3.4 fold, the K28E

9 aqMutL retained significant activity. Moreover, the $\mathrm{pH}$ dependence of the $k_{\text {cat }}$ values still exhibited the $\mathrm{p} K_{\mathrm{a}}$ value, 9.2, of the general acid catalyst (Fig. 5B). These results indicate that Lys28 is involved, but not essential, in the catalysis and that another residue serves as the general acid for the catalysis.

Dimerization of the ATPase domain seems to be necessary for the ATPase activity of aqMutL.

Around the ATP-binding site in the crystal structure of the aqMutL NTD, there is no other amino acid residue whose side chain is expected to have an alkaline $\mathrm{p} K_{\mathrm{a}}$ value (Fig. $3 \mathrm{~A}$ ). Then, we suspected that, in the catalytic process of the ATPase reaction, unstructured loop regions of aqMutL might transform into the ordered structures just like the ATP-bound state of $E$. coli MutL. In E. coli MutL, the ATP binding induces transformation of the unstructured loop regions into the dimeric interface, in which Arg95 and Asn302 are included (23,43). The R95F/N302A double mutation has been reported to decrease the ATPase activity of E. coli MutL by 60 fold: an evidence that the transformation of the loop regions and the resulting dimerization of the ATPase domain are essential for the ATP hydrolysis by E. coli MutL. Our previous study revealed that 
1 the R95W mutation had no effect on the ATPase activity of aqMutL (36). Then, we examined

2 the effect of the substitution of an alanine for Asn282 of aqMutL that corresponds to Asn302 of

3 E. coli MutL. The CD measurements of the N282A aqMutL showed that the mutation does not

4 influence the structure and stability of monomer aqMutL (Fig. 4A and B). The $k_{\text {cat }}$ value of the

$5 \quad \mathrm{~N} 282 \mathrm{~A}$ aqMutL was 52 -fold smaller than that of the wildtype aqMutL (Fig. 5A and Table 1),

6 indicating that the dimeric structure of the ATPase domain is also transiently formed in aqMutL

7 during the catalysis.

8

A

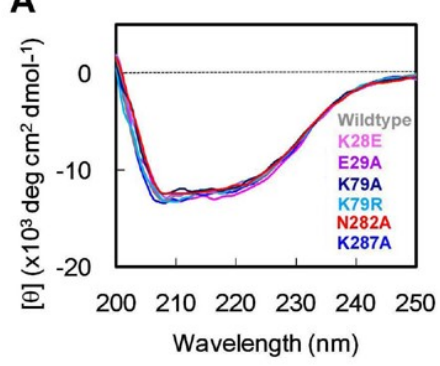

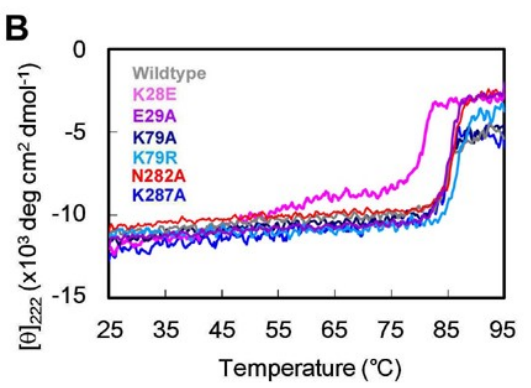

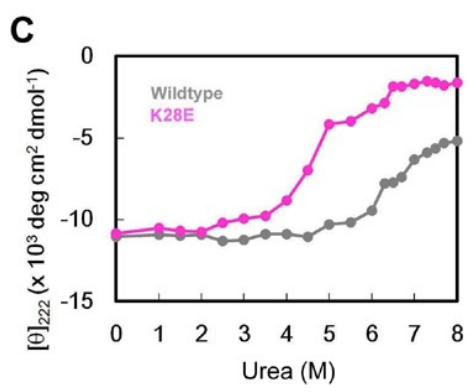

9

Figure 4. CD measurements of the wildtype and mutant aqMutLs. (A) Far-UV CD spectra. Each dependent denaturation was monitored by measuring the residue molar ellipticity at $222 \mathrm{~nm}$. (C) Urea-

14 dependent denaturation of the wildtype and the K28E aqMutLs. The residue molar ellipticities at $222 \mathrm{~nm}$ were plotted against urea concentrations $(0-8 \mathrm{M})$. 
1 Table 1. Kinetic parameters for the ATPase activity of aqMutLs, ProS2-tagged human PMS2 NTDs,

2 histidine-tagged human MLH1 NTDs, and $A$. aeolicus GyrB NTDs.

\begin{tabular}{|c|c|c|}
\hline Proteins & $k_{\text {cat }}\left(\min ^{-1}\right)^{1}$ & $K_{\mathrm{m}}(\mathrm{mM})^{1}$ \\
\hline aqMutL WT & $1.5 \pm 0.15$ & $0.36 \pm 0.19$ \\
\hline $\mathrm{K} 28 \mathrm{E}$ & $0.44 \pm 0.022$ & $0.90 \pm 0.073$ \\
\hline E29A & N.D. ${ }^{2}$ & N.D. ${ }^{2}$ \\
\hline K79A & N.D. ${ }^{2}$ & N.D. ${ }^{2}$ \\
\hline K79R & $0.17 \pm 0.014$ & $0.61 \pm 0.13$ \\
\hline $\mathrm{N} 282 \mathrm{~A}$ & $0.029 \pm 0.0010$ & $0.56 \pm 0.054$ \\
\hline K287A & $0.46 \pm 0.023$ & $0.37 \pm 0.036$ \\
\hline PMS2 WT & $0.37 \pm 0.018$ & $0.19 \pm 0.039$ \\
\hline K91A & N.D. ${ }^{2}$ & N.D. ${ }^{2}$ \\
\hline K91R & $0.044 \pm 0.0017$ & $0.30 \pm 0.042$ \\
\hline K340A & $0.063 \pm 0.0081$ & $0.16 \pm 0.093$ \\
\hline $\mathrm{K} 340 \mathrm{E}$ & $0.029 \pm 0.0018$ & $0.080 \pm 0.012$ \\
\hline MLH1 WT & $0.16 \pm 0.0065$ & $0.79 \pm 0.075$ \\
\hline K84A & N.D. ${ }^{2}$ & N.D. ${ }^{2}$ \\
\hline K84E & N.D. ${ }^{2}$ & N.D. ${ }^{2}$ \\
\hline $\mathrm{K} 311 \mathrm{E}$ & $0.020 \pm 0.0030$ & $0.75 \pm 0.13$ \\
\hline aqGyrB WT & $2.2 \pm 0.13$ & $0.25 \pm 0.041$ \\
\hline K109A & N.D. ${ }^{2}$ & N.D. ${ }^{2}$ \\
\hline
\end{tabular}

$3 \quad{ }^{1}$ The standard Michaelis-Menten equation was fitted to the data to determine the $k_{\text {cat }}$ and $K_{\mathrm{m}}$ values.

$4 \quad{ }^{2}$ N.D. means that the activity was not detected. 
1 We constructed a model structure of the ATP-bound dimeric form of the aqMutL NTD by using

2 the ATP analog-bound state of the E. coli MutL NTD as a template structure for homology

3 modeling. A single subunit of the resulting dimer is shown in Fig 3B. In the model structure,

4 the side chains of Lys 79 and Lys287 interacted with the $\beta$ - and $\gamma$-phosphoryl groups of ATP,

5 respectively. The interaction of Lys79 with the $\beta$-phosphoryl group of ATP has already been

6 mentioned in a previous study (23). Both Lys79 and Lys287 are not included in the Bergerat

$7 \quad$ ATP-binding fold, but conserved in all MutL proteins (Fig. 1). As for Lys287, the corresponding

8 residue Lys307 of E. coli MutL has been shown to be involved in the ATPase activity; the $k_{\text {cat }}$

9 value of the K307A E. coli MutL is 20 -fold smaller than that of the wildtype (23). The lysine residue corresponding to Lys79 of aqMutL has not been investigated in in vitro experiments with

MutLs from any species. Previously, a genetic study reported that the substitution of a glutamate for this lysine residue resulted in the loss of in vivo MMR activity in Bacillus subtilis (44). It was also shown that the mutation resulted in the absence of MutL protein in the B. subtilis cell. Therefore, involvement of the lysine residue in the ATPase hydrolysis has been unclear. It should be noted that Lynch syndrome-associated mutations K91R and K84E, the corresponding lysine residues of human PMS2 and MLH1, respectively, have been clinically described and classified as VUSs.

Not Lys287 but Lys79 is the general acid catalyst for the ATPase activity of aqMutL.

We prepared the K79A and K287A aqMutLs. Both mutant aqMutLs were properly folded and as stable against heat as the wildtype protein (Fig. 4A and B). The K287A aqMutL retained the ATPase activity; the mutation reduced the $k_{\text {cat }}$ value by 3.3 fold with little effect on the $K_{\mathrm{m}}$ value

(Fig. 5A and Table 1). The $\mathrm{pH}$ profile of the $k_{\text {cat }}$ values of the K287A aqMutL exhibited the $\mathrm{p} K_{\mathrm{a}}$ 
1 value of 9.3 (Fig. 5B), indicating that Lys 287 is not the general acid. Since the $\varepsilon$-amino group

2 of Lys287 is expected to interact with the $\gamma$-phosphoryl group of ATP (Fig. 3B), Lys287 might

3 act as a Lewis acid that provides the positive charge to stabilize a negatively charged transient

4 intermediate. On the other hand, the K79A mutation resulted in a complete loss of the ATPase

5 activity (Fig. 5A). The loss of the activity was also observed when the general base Glu29 was

6 replaced by an alanine (Fig. 5A).

7

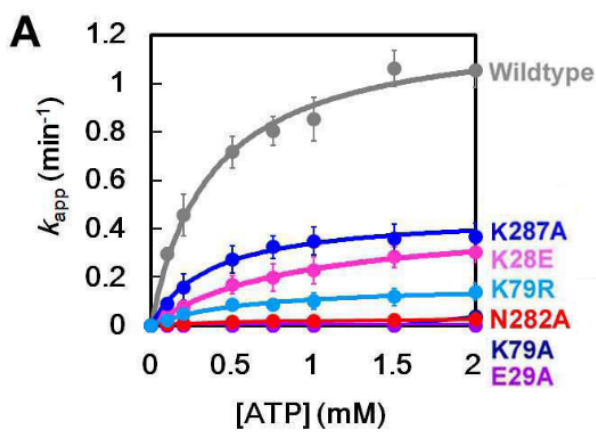

[ATP] (mM)
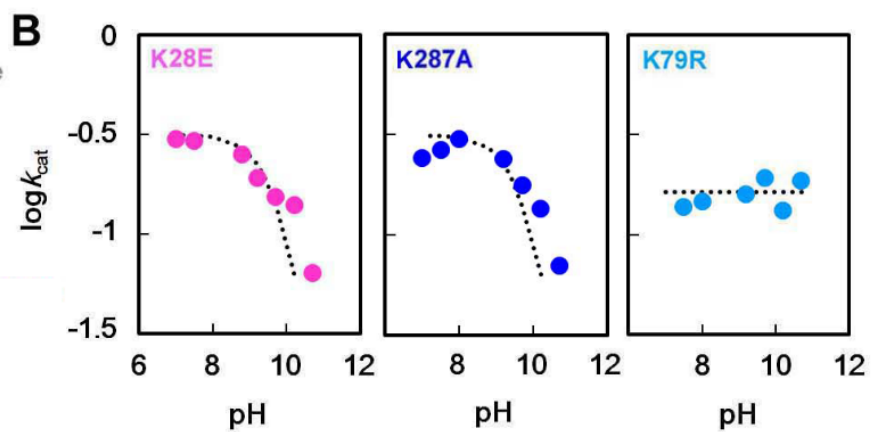

Figure 5. ATPase activity of the wildtype and mutant aqMutLs. (A) The ATPase activity was measured at $70^{\circ} \mathrm{C}$ by monitoring the release of phosphate ions with BIOMOL Green. The apparent rate constants were plotted against ATP concentrations. Average values from three independent experiments are shown with standard deviations. Theoretical Michaelis-Menten curves are overlaid. (B) The $\log k_{\text {cat }}$ values of the K28E, K287A, and K79R aqMutLs were plotted against pH. Dotted lines for the K28E and K287A aqMutLs are theoretical curves derived with $\mathrm{p} K_{\mathrm{a}}$ values 9.2 and 9.3 , respectively.

In order to exclude the possibility that Lys79 is involved in the ATP binding, not the catalysis, trypsin limited proteolysis of the K79A aqMutL NTD was performed in the presence of an ATP analog, AMPPNP. It was previously shown that the ATP binding induced conformational changes 
1 of the aqMutL NTD, resulting in alteration of the digestion pattern by trypsin (36). As shown in

2 Fig. S2A, the digestion pattern of the E29A aqMutL NTD, of which the ATP-binding ability was

3 significantly reduced $(23,36)$, was not influenced by the presence of AMPPNP. On the other hand,

4 the digestion pattern of the K79A aqMutL NTD was almost the same as that of the wildtype NTD.

5 The ATP-binding ability of the K79A aqMutL NTD was also examined by equilibrium dialysis

6 (Fig. S2B), which revealed that the $K_{\mathrm{d}}$ values of the wildtype and K79A aqMutL NTDs for

7 AMPPNP were $0.30 \mathrm{mM}$ and $0.34 \mathrm{mM}$, respectively. These results indicate that Lys79 is not

8 involved in the ATP binding.

9

10

11

\begin{tabular}{|c|c|c|c|}
\hline A & Wildtype & E29A & K79A \\
\hline Trypsin & + & - & \\
\hline
\end{tabular}

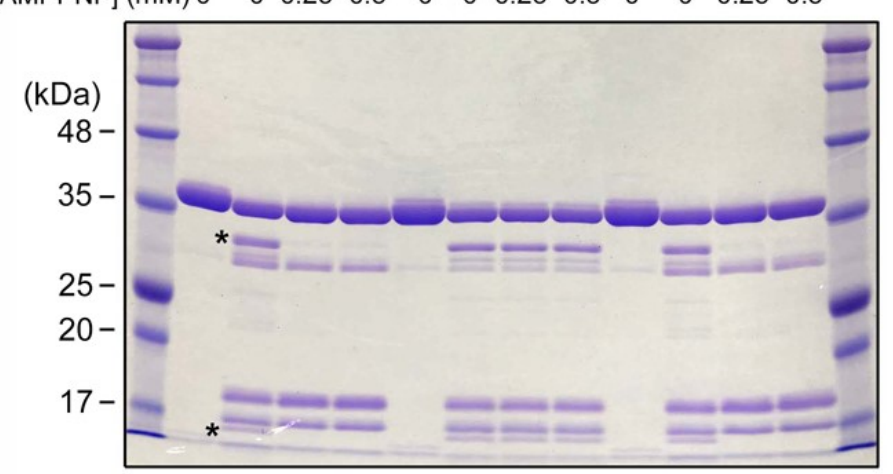

B

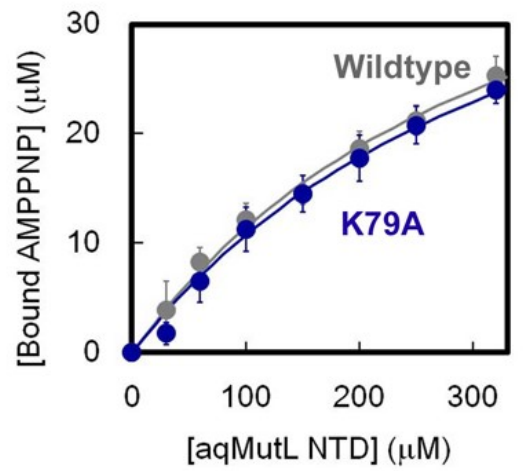

Supplementary Figure S2. The K79A aqMutL NTD retained the ATP-binding ability. (A) Trypsin limited proteolysis of the wildtype, E29A, and K79A aqMutL NTDs was performed in the presence of $0,0.25$, and $0.5 \mathrm{mM}$ AMPPNP. In the experiments with the wildtype and K79A aqMutL NTDs, the presence of AMPPNP prevented the generation of fragments indicated by asterisks. (B) Binding affinity was quantified by equilibrium dialysis. For each protein concentration, the concentration of unbound AMPPNP was determined on the basis of the absorbance at $260 \mathrm{~nm}$ of the solution from the buffer chamber after equilibrium was attained (see Materials and Methods). The concentrations of bound AMPPNP were calculated by subtracting those of unbound AMPPNP from the total 
1 concentration, and plotted against the protein concentrations. Average values from three independent

2 experiments are shown with standard deviations. Theoretical curves with the $K_{\mathrm{d}}$ values of $0.30 \mathrm{mM}$

3 and $0.34 \mathrm{mM}$ for the wildtype and K79A aqMutL NTDs, respectively, are overlaid.

To test whether Lys79 is the general acid, we created the K79R aqMutL and examined its 7 physicochemical properties and ATPase activity. The CD measurements revealed that the K79R 8 mutation did not influence the structure and stability of the protein (Fig. 4A and B). As shown

9 in Fig. 5A and Table 1, K79R retained the ATPase activity, although the mutation resulted in an 8.8-fold decrease in the $k_{\text {cat }}$ value. Importantly, the $k_{\text {cat }}$ values of the K79R aqMutL exhibited no $\mathrm{pH}$ dependency in the alkaline $\mathrm{pH}$ region (Fig. 5B). The $\mathrm{p} K_{\mathrm{a}}$ of the guanidino group of arginine (12.5 in its free amino acid form) is much higher than that of the $\varepsilon$-amino group of lysine (10.0). The apparent disappearance of the $\mathrm{p} K_{\mathrm{a}}$ in the $\mathrm{pH}$ profile would thus be a consequence of the alkaline shift of the $\mathrm{pH}$ dependence of the activity. These findings indicate that Lys79 is the general acid catalyst and that the arginine residue at the position 79 is not optimal but still functional as the general acid.

The lysine residues corresponding to aqMutL Lys79 are also essential for the ATPase activity of human PMS2 and MLH1. forms of the human PMS2 NTD were prepared. The K340A and K340E PMS2 NTDs exhibited weakened, but substantial, ATPase activities, whose $k_{\text {cat }}$ values were 5.9- and 13-fold smaller than 
1 that of the wildtype (Fig. 6A and Table 1). In contrast, the K91A mutation completely abolished

2 the ATPase activity of the human PMS2 NTD (Fig. 6A). In addition, the K91R PMS2 NTD

3 retained the ATPase activity, although the $k_{\text {cat }}$ value was decreased by 8.4 fold (Fig. $6 \mathrm{~A}$ and Table

$4 \quad 1)$.

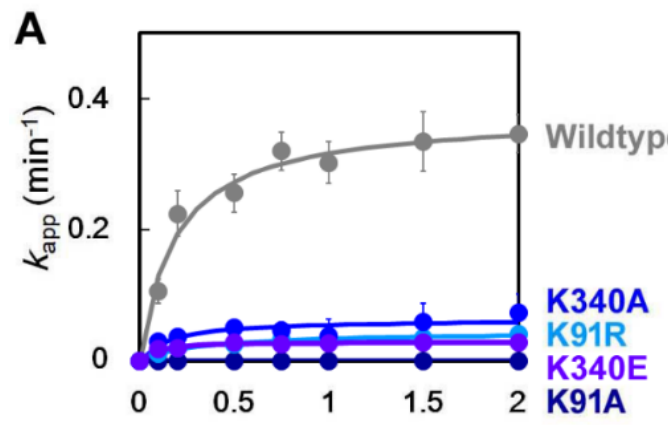

[ATP] $(\mathrm{mM})$

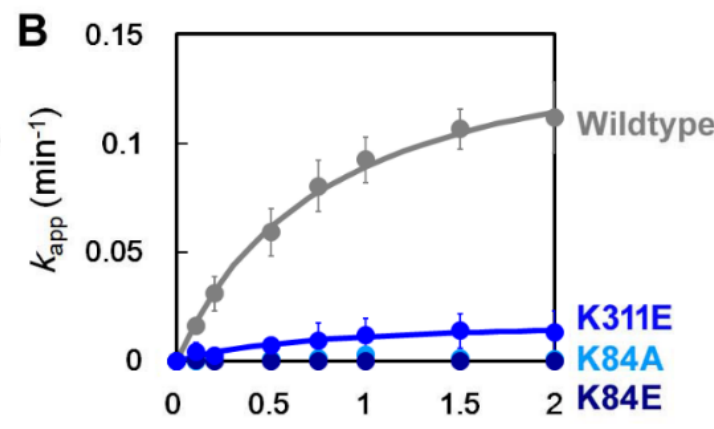

[ATP] (mM)
7

Figure 6. ATPase activity of the wildtype and mutant ProS2-fused human PMS2 NTDs (A) and histidine-tagged human MLH1 NTDs (B). The K91R and K340E mutations are clinically found in human PMS2. Similarly, K84E and K311E are the clinically-found mutations of human MLH1. The ATPase activity was measured at $37^{\circ} \mathrm{C}$. The average values from three independent experiments are shown with standard deviations. Theoretical Michaelis-Menten curves are overlaid.

The same results were obtained for the human MLH1 NTD. Lys79 and Lys287 of aqMutL correspond to Lys84 and Lys311, respectively, in human MLH1. As shown in Fig. 6B and Table 1, the K311E MLH1 NTD retained a weak ATPase activity; the $k_{\text {cat }}$ value was 8.0 -fold smaller than that of the wildtype. On the other hand, the activity was completely abolished by the K84A and K84E mutations; the latter mutation was found in Lynch syndrome-suspected patients and diminished the MMR activity in the human cell lysate without decrease in the protein expression 
1 (45). Since human MutL homologs were not stable at alkaline $\mathrm{pHs}$, the $\mathrm{pH}$ profile of the ATPase

2 activity could not be examined.

3 The results for these mutant forms of aqMutL, the human PMS2 NTD, and the human MLH1

4 NTD were consistent with each other, which strongly supports the notion that the lysine residue

$5 \quad$ corresponding to Lys79 of aqMutL serves as the general acid in the MutL reaction.

6 As for another lysine residue, the recombinant K40E PMS2 NTD, which corresponds to the

$7 \quad \mathrm{~K} 28 \mathrm{E}$ aqMutL, was degraded in the host E. coli cell probably due to the mutation-induced

8 destabilization of the protein structure. Similarly, the K33E MLH1 NTD precipitated during

9 overexpression in the host cell. These are in agreement with the result that K28E mutation in aqMutL resulted in the decreased protein stability (Fig. 4B and 4C). Previously, we reported that another Lynch syndrome-associated mutation S34I of aqMutL (S46I of human PMS2), which is at the Bergerat ATP-binding fold, also reduces stability of the overall protein structure through destabilization of a local structure around the ATP-binding site (36). Integrity of the Bergerat ATP-binding fold would be essential for the structural stability of MutL.

The ATPase activity-related lysine residues are essential for MMR in vivo.

As described above, three lysine residues, Lys28, Lys79, and Lys287, are involved in the in vitro

ATPase activity. Importance of the three lysine residues in the MMR activity in the cell was examined by the phenotype complementation experiments using a eubacterium, Thermus thermophilus, one of the model organisms that has been utilized for studies on DNA repair including MMR (46,47). Dysfunction of MMR causes a significant increase in spontaneous mutation frequency that can be measured as the frequency of streptomycin-resistant bacterial cells 
1 (47). As shown in Fig. 7, the frequency of streptomycin-resistant cells of the mutL-lacking $T$.

2 thermophilus strain was approximately 10-fold higher than that of the wildtype strain.

4

$5 \quad$ Figure 7. Phenotype complementation assay using T. thermophilus. (A) Protein expression in $T$.

A

Anti MutL

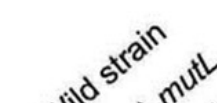

$D^{m u}$
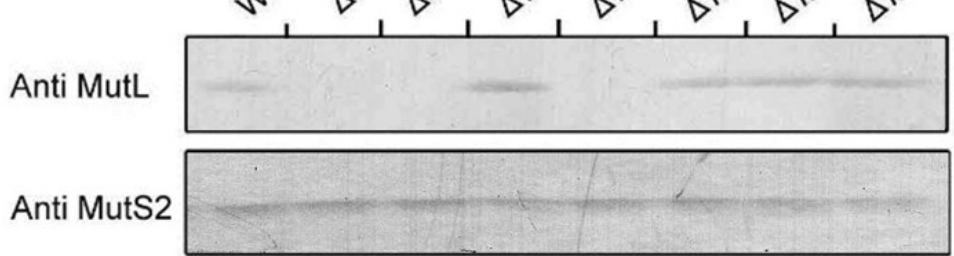

B

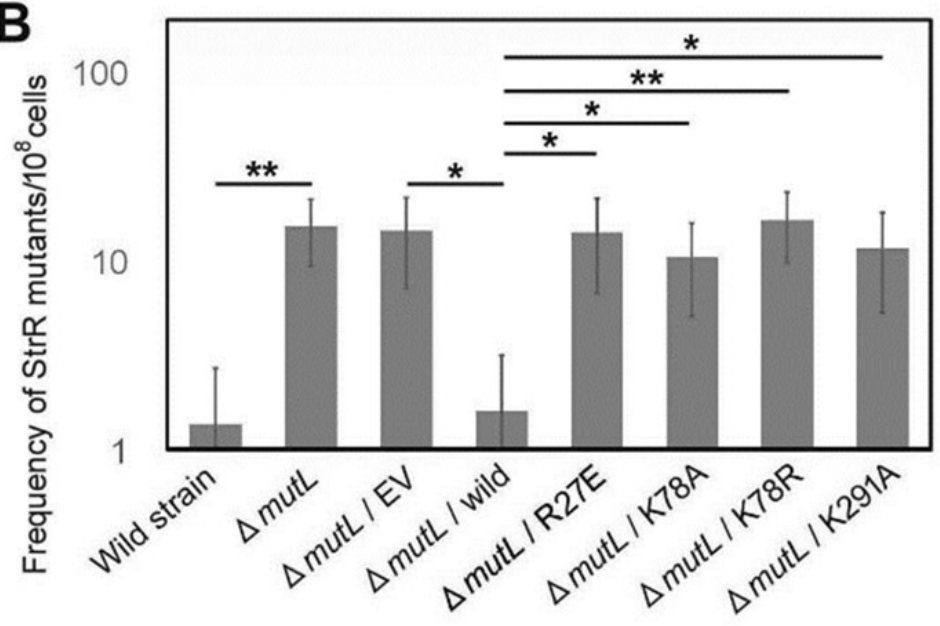

6 analyses were performed with the two-sided Student's $t$ test: *, $p<0.05 ;{ }^{* *}, p<0.01$. 
1 Western blot analysis showed that introduction of the wildtype T. thermophilus mutL gene led

2 to successful expression of the gene in the mutL-lacking strain (Fig. 7A). Expression of the

3 wildtype $m u t L$ gene reduced the mutability of the $m u t L$-lacking strain to a level equal to that of

4 the wildtype strain (Fig. 7B). In contrast, the mutL gene carrying the R27E mutation, which

5 corresponds to the K28E mutation of aqMutL, did not complement the hyper mutator phenotype

6 of the disruptant (Fig. 7B). Interestingly, Western blot analysis revealed that the R27E $T$.

7 thermophilus MutL was absent (Fig. 7A) probably due to degradation in the cell. This is

8 consistent with the result that the K28E aqMutL was unstable compared with the wildtype protein.

9 Genes for the K78A, K78R, and K291A T. thermophilus MutLs, which correspond to the K79A,

$10 \mathrm{~K} 79 \mathrm{R}$, and K287A aqMutLs, were also introduced into the mutL-lacking T. thermophilus.

11 Although Western blot analysis confirmed the successful expression of these variant genes in the cell (Fig 7A), these did not complement the hyper mutator phenotype of the $m u t L$-lacking strain

(Fig. 7B). These results indicate that the lysine residues are critical for in vivo MMR and that the reduction of the in vitro ATPase activity by only 3 fold results in almost loss of the in vivo MMR activity.

Catalytic mechanism of the ATPase activity of MutL.

Based on the results presented above, we propose a catalytic mechanism of the MutL ATPase activity (Fig. 8). Since phosphorus is able to form trivalent, tetravalent, and pentavalent compounds, a phosphoryl transfer reaction can proceed by either of associative and dissociative mechanisms. In the dissociative mechanism, the $\gamma$-phosphate of ATP is first eliminated to generate a metaphosphate ion $\left(\mathrm{PO}_{3}^{-}\right)$and $\mathrm{ADP}$, and, then, a nucleophile $\left(\mathrm{HO}^{-}\right)$activated by a general base is added to the metaphosphate. In previous reports, T. thermophilus and E. coli MutLs carrying 
1 mutations at the general base Glu29 were not able to generate the product ADP $(23,48)$. These

2 support that the ATP hydrolysis by MutL does not proceed by the dissociative mechanism.

3 Therefore, we propose the following catalytic mechanism based on the associative mechanism:

4 The general base Glu29 of aqMutL orients and activates the nucleophilic water molecule. The

$5 \quad$ nucleophilic attack of the water molecule to the $\gamma$-phosphoryl group of ATP generates a transient

6 pentacovalent intermediate, which is stabilized by the positive charge of the $\varepsilon$-amino group of the

7 Lewis acid Lys287. Subsequently, Lys79, the general acid catalyst, donates a proton to the $\beta$ -

8 phosphoryl group to complete the cleavage reaction.

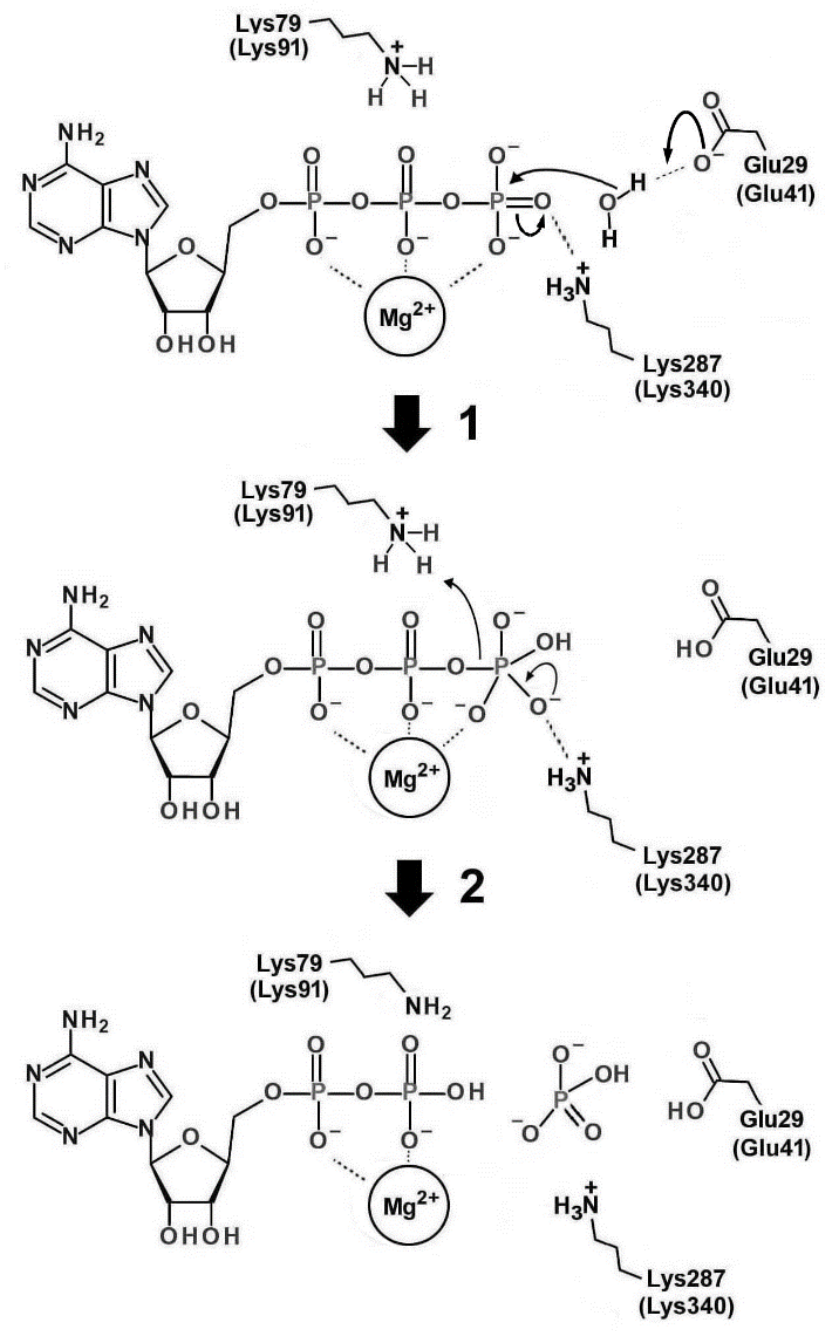


1 Figure 8. A model for the catalytic mechanism of the MutL ATPase reaction. Numbering of the

2 amino acid residues is based on the numbering of the aqMutL sequence. Numbering of the human

3 PMS2 is indicated in the parentheses. ATP and magnesium ion are bound at the ATPase active site

4 of MutL. Step 1: The nucleophilic water molecule is coordinated and activated by the general base

5 Glu29. Attack of the nucleophilic water to the $\gamma$-phosphoryl group generates a transient

6 pentacovalent intermediate with an extra negative charge, which is stabilized by the positive charge

7 from Lys287. Step 2: Instability of the negative charge on the phosphoryl oxygen leads to re-

8 formation of a double bond and collapse of the intermediate, breaking the phosphoanhydride bond

9 between the $\beta$ - and $\gamma$-phosphoryl groups. The general acid Lys79 provides a proton to the $\beta$-phosphoryl group, facilitating the bond breakage. of E. coli GyrB, another GHKL superfamily ATPase (Fig. S3A-C). It has been considered that, in the ATPase reaction of E. coli GyrB, Glu42 serves as a general base to activate the nucleophilic water molecule and that Lys337 stabilizes the negatively-charged intermediate $(49,50)$. It was previously reported that substitutions of Ile, Thr, or Glu for Lys103 of E. coli GyrB completely abolished the ATPase activity (51), although another study reported that the K103I and K103A E. coli GyrBs retained slightly-weakened ATPase activities (52). We assessed the effect of the Ala substitution at the corresponding Lys residue (Lys109) on the ATPase activity of the $A$. aeolicus GyrB (aqGyrB) NTD. As shown in Fig. S3D and Table 1, the ATPase activity of the general acid in aqGyrB. 
A

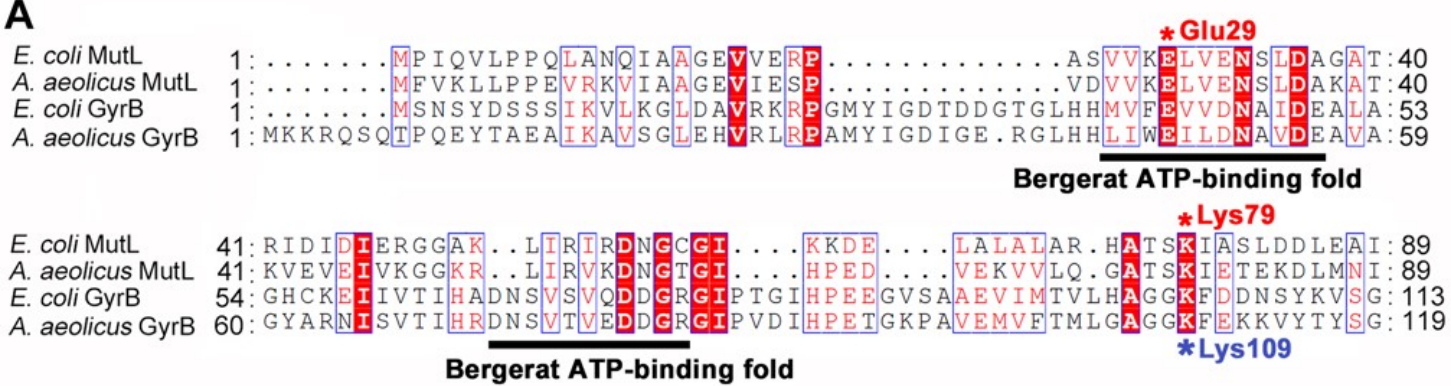

B

C
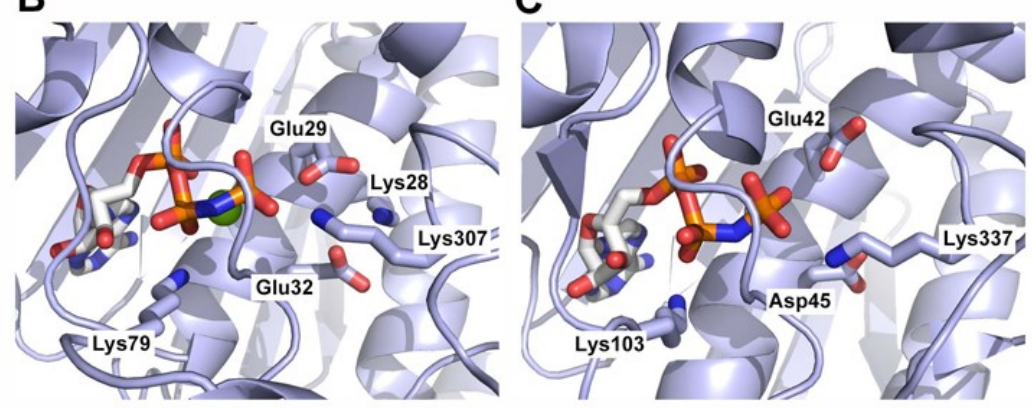

D

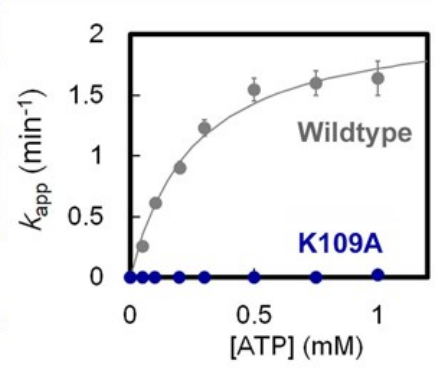

Supplementary Figure S3. ATPase activity of GyrB. (A) Amino acid sequence alignment of MutL

4

Pathogenicity of the Lynch syndrome-associated VUSs. 
1 Various Lynch syndrome-associated mutations of human PMS2 and MLH1 have been found at

2 the lysine residues, of which the involvement in the ATPase activity was revealed by the present

3 study. The pathogenicity of the K91R and K340E mutations of human PMS2 can be explained

4 by reduction in the ATPase activity, and so be the mutations K84E and K311E of human MLH1.

5 The K40E and K33E mutations of human PMS2 and MLH1, respectively, would be pathogenic

6 because these mutations destabilize the protein structure. Thus, pathogenicity of these

7 previously-found VUSs in MutL homologs can now be clearly explained.

8

Construction of expression plasmids.

\section{Materials and Methods}

The expression plasmids for the K28E, E29A, K79A, K79R, N282A, and K287A full-length aqMutLs were constructed by introducing the mutations into the pET-11a/aqmutL plasmid (47) using the PrimeSTAR mutagenesis procedure (Takara). The primer sets used for the construction of these mutant aqMutLs were 5'-TCGTAGAGGAACTCGTTGAGAATTCT-3' and

5'-CGAGTTCCTCTACGACGTCAACAGGA-3',

AACGAGCGCCTTTACGACGTCAACAGG-3',

CTCTATCGCACTCGTCGCTCCCTGCAG-3', 
2 TTCCTTTGCCTTGGGGTGGACGTTGAA-3', respectively. NTDs (residues 1-365) were constructed by introducing the mutations into the pCold ProS2/human PMS2 NTD plasmid (36) using the PrimeSTAR mutagenesis procedure. The

6 primer sets used were 5'-GCGGTAGAGGAGTTAGTAGAAAACAG-3' and 5'-

7 TAACTCCTCTACCGCAGTGCTTAGACT-3', 5'-CATCTGCGATTCAAGAGTTTGCCGA-3'

8 and 5'-TTGAATCGCAGATGTGTGATGTTTCA-3',

9 5'-CATCTAGGATTCAAGAGTTTGCCGA-3' and 5'-

TTGAATCCTAGATGTGTGATGTTTCA-3', 5'-TCCAGATGCAAGGCAAATTTTGCTACA-

and

5'-TGCCTTGCATCTGGAGTAACATTGAT-3',

and

$5^{\prime}-$ TGCCTTTCATCTGGAGTAACATTGAT-3', respectively.

The cDNA of human MLH1 was obtained from the National Institute of Technology and Evaluation (Kisarazu, Japan). The nucleotide sequence corresponding to the NTD of human MLH1 (residues 1-337) was amplified by PCR using the primer set 5'-

TATCTCGAGTTAGCCCAGGAGCTTGCTCTC-3' (underlines indicate NdeI and XhoI sites, respectively). The amplified fragment was digested with NdeI and XhoI and ligated into the corresponding sites of the pET28-MHL (37) to obtain the pET28-MHL/human MLH1 NTD. The expression plasmids for the K33E, K84E, K84A, and K311E human MLH1 NTD were constructed by introducing the mutations into the pET28-MHL/human MLH1 NTD plasmid using the PrimeSTAR mutagenesis procedure. The primer sets used were 5'- 
1 ATCTCTTCGATAGCATTAGCTGGCCG-3', 5'-TACTAGTGAACTGCAGTCCTTTGAGG-

2 3' and 5'-TGCAGTTCACTAGTAGTGAACCTTTC-3', $\quad$ 5'-

3 TACTAGTGCACTGCAGTCCTTTGAGG-3' 5'-

4 TGCAGtgCACtagtagtgaACCTTTC-3', 5'-

5 CCCCACAGAGCATGAaGTTCACTTCC-3' ${ }^{\prime}$ and

6 TCATGCTCTGTGGGGTGCACATTAAC-3'.

$7 \quad$ The nucleotide sequence encoding the NTD (residues 1-397) of aqGyrB was amplified by

8 PCR using the A. aeolicus genomic DNA as a template. The following primers were used: 5'-

9 ATACATATGAAGAAAAGGCAGTCTCAAACC-3'

10 ATGGATCCTTAAACGAGTTCCTTAGCTTTTTTTGC-3' (underlines indicate NdeI and

11 BamHI sites, respectively). The amplified DNA fragment was digested with NdeI and BamHI

12 and ligated into the corresponding sites of the pET-11a (Novagen) to obtain the pET-11a/aqgyrB

13 NTD. The expression plasmid for the K109A mutant form of the aqGyrB NTD was constructed

14 by introducing the mutation into the pET-11a/aqgyrB NTD plasmid using the PrimeSTAR

15 mutagenesis procedure with the primers: 5'-GGAGGAGCGTTTGAAAAGAAAGTCTA-3' and

16 5'-TTCAAACGCTCCTCCCGCCCCGAGCAT-3'.

17 Sequence analyses revealed that, apart from the desired mutations, no unintended mutation

18 was introduced into the $A$. aeolicus $m u t L$, gyrB, human PMS2 and MLH1 genes.

Expression and purification of proteins.

The histidine-tagged human MLH1 NTD was prepared using the modified procedure of the previously-described method (37). Rosetta2(DE3) pLysS E. coli competent cells were transformed with the pET28-MHL/human MLH1 NTD carrying the wildtype, K33E, K84A, K84E, or K311E NTD gene. One liter of LB medium (Difco) containing $50 \mu \mathrm{g} / \mathrm{ml}$ kanamycin and 30 
$1 \mu \mathrm{g} / \mathrm{ml}$ chloramphenicol was inoculated with $5 \mathrm{ml}$ of overnight preculture. After $4 \mathrm{~h}$ of

2 cultivation at $37^{\circ} \mathrm{C}$, isopropyl- $\beta$-D-thiogalactopyranoside was added to a final concentration of

$30.2 \mathrm{mM}$. The cells were further cultivated at $15^{\circ} \mathrm{C}$ for $24 \mathrm{~h}$ and harvested by centrifugation.

4 The cells were re-suspended with $20 \mathrm{ml}$ of $50 \mathrm{mM}$ Tris- $\mathrm{HCl}(\mathrm{pH} 8.0)$ containing $500 \mathrm{mM} \mathrm{NaCl}$,

$55 \%$ glycerol, and $0.5 \%$ CHAPS, and disrupted by sonication on ice. After centrifugation at

$648,000 \times \mathrm{g}$ for $20 \mathrm{~min}$, the supernatant was loaded onto a His-bind resin column (Merck Millipore)

$7 \quad(1 \mathrm{ml})$ pre-equilibrated with buffer I containing $20 \mathrm{mM}$ Tris- $\mathrm{HCl}(\mathrm{pH} 8.0), 5 \%$ glycerol, and 500

$8 \mathrm{mM} \mathrm{NaCl}$. The column was washed with $2 \mathrm{ml}$ of buffer I and further washed with $10 \mathrm{ml}$ of buffer

9 I containing $50 \mathrm{mM}$ imidazole. The column was eluted with $6 \mathrm{ml}$ of buffer I containing $100 \mathrm{mM}$

EDTA. The fractions containing the histidine tagged human MLH1 NTD were collected and dialyzed against $50 \mathrm{mM}$ Tris- $\mathrm{HCl}(\mathrm{pH} 8.0), 5 \%$ glycerol, and $250 \mathrm{mM} \mathrm{NaCl}$. The protein solution was loaded onto a Toyopearl SP-650 column (TOSOH) $(10 \mathrm{ml})$ pre-equilibrated with 20 $\mathrm{mM}$ Tris- $\mathrm{HCl}(\mathrm{pH} 8.0$ ) containing $20 \mathrm{mM} \mathrm{NaCl}$. The column was washed with $50 \mathrm{ml}$ of $20 \mathrm{mM}$ Tris- $\mathrm{HCl}(\mathrm{pH} 8.0$ ) containing $100 \mathrm{mM} \mathrm{NaCl}$. The column was eluted with $15 \mathrm{ml}$ of $20 \mathrm{mM}$ Tris$\mathrm{HCl}(\mathrm{pH}$ 8.0) containing $250 \mathrm{mM} \mathrm{NaCl}$. The protein solution was concentrated and stored at $4^{\circ} \mathrm{C}$.

The wildtype and mutant forms of the full-length aqMutL and the aqMutL NTD were overexpressed in E. coli and purified as previously described $(36,47)$. The wildtype and mutant forms of the human ProS2-fused PMS2 NTD were also overexpressed in E. coli and purified by the previously-described procedure (36).

The wildtype and K109A aqGyrB NTDs were overexpressed in E. coli by the same procedure as that for aqMutL. The cells were lysed and heat-treated at $70^{\circ} \mathrm{C}$ for $10 \mathrm{~min}$ and immediately chilled on ice for $10 \mathrm{~min}$. After centrifugation at $48,000 \times \mathrm{g}$ for $20 \mathrm{~min}$, the supernatant was loaded onto a Toyopearl SP column $(20 \mathrm{ml})(\mathrm{TOSOH})$ pre-equilibrated with 30 
$1 \mathrm{mM}$ Tris- $\mathrm{HCl}(\mathrm{pH}$ 8.0). The column was washed with $30 \mathrm{ml}$ of $30 \mathrm{mM}$ Tris- $\mathrm{HCl}(\mathrm{pH} 8.0)$ and

2 further washed with $60 \mathrm{ml}$ of $30 \mathrm{mM}$ Tris- $\mathrm{HCl}(\mathrm{pH} 8.0)$ containing $0.5 \mathrm{M} \mathrm{NaCl}$. The column

3 was eluted with $60 \mathrm{ml}$ of $30 \mathrm{mM}$ Tris- $\mathrm{HCl}(\mathrm{pH} 8.0)$ containing $1.0 \mathrm{M} \mathrm{NaCl}$. The fractions containing aqGyrB NTD were detected by SDS-PAGE and collected. Ammonium sulfate was added to the fractions to yield a final concentration of $1 \mathrm{M}$. The solution was loaded onto a Toyopearl Phenyl column (10 ml) (TOSOH) equilibrated with $30 \mathrm{mM}$ Tris- $\mathrm{HCl}(\mathrm{pH} 8.0)$ containing $1 \mathrm{M}$ ammonium sulfate. The column was washed with $30 \mathrm{ml}$ of $30 \mathrm{mM}$ Tris- $\mathrm{HCl}(\mathrm{pH}$ 8.0) containing $1 \mathrm{M}$ ammonium sulfate and further washed with $30 \mathrm{ml}$ of $30 \mathrm{mM}$ Tris- $\mathrm{HCl}(\mathrm{pH}$

9 8.0) containing $0.3 \mathrm{M}$ ammonium sulfate. Then, the column was eluted with $50 \mathrm{ml}$ of $30 \mathrm{mM}$ Tris- $\mathrm{HCl}(\mathrm{pH} 8.0)$. The fractions containing the protein $(30 \mathrm{ml})$ were collected and dialyzed against one liter of $30 \mathrm{mM}$ Tris- $\mathrm{HCl}\left(\mathrm{pH} \mathrm{8.0)}\right.$ three times at $4^{\circ} \mathrm{C}$. The protein solution was concentrated and stored at $4^{\circ} \mathrm{C}$.

CD spectrometry.

CD measurements were performed with the Jasco spectropolarimeter, model J-720W (Jasco).

Measurements of CD spectra were carried out in a solution comprised of $50 \mathrm{mM}$ potassium phosphate $(\mathrm{pH} 7.0)$ and $\sim 10 \mu \mathrm{M}$ protein using a $0.1-\mathrm{cm}$ cell at $25^{\circ} \mathrm{C}$. The residue molar ellipticity [ $\theta$ ] was defined as $100 \theta_{\text {obs }} /(l c)$, where $\theta_{\text {obs }}$ is the observed ellipticity, $l$ is the length of the light path in centimeters, and $c$ is the residue molar concentration of the protein. The temperature scans were carried out with a heating rate of $1^{\circ} \mathrm{C} / \mathrm{min}$ controlled by the Jasco programmable Peltier element. $16 \mathrm{~h}$. 
For the measurements of CD spectra under different $\mathrm{pH}$ conditions, $30 \mathrm{mM}$ sodium acetate,

$230 \mathrm{mM}$ MES-NaOH, $30 \mathrm{mM}$ Tris- $\mathrm{HCl}$, or $30 \mathrm{mM}$ sodium carbonate/bicarbonate was used to

respectively. After incubation of $\sim 10 \mu \mathrm{M}$ protein at $60^{\circ} \mathrm{C}$ for $3 \mathrm{~h}, \mathrm{CD}$ spectra from 200 to 250 nm were measured.

7 ATPase assay.

8 The ATPase activity of aqMutL, the histidine-tagged human MLH1 NTD, and the ProS2-fused 9 human PMS2 NTD was assayed by the previously described procedure $(36,53)$. The assay was carried out with $10 \mu \mathrm{M}$ protein in a $20-\mu \mathrm{L}$ reaction mixture comprised of $50 \mathrm{mM}$ HEPES-KOH (pH 7.5), $100 \mathrm{mM} \mathrm{NaCl}, 5 \mathrm{mM} \mathrm{MgCl} \mathrm{m}_{2}$ and various concentrations of ATP. The reactions were performed at $70^{\circ} \mathrm{C}$ for 60 min with aqMutL and the aqGyrB NTD. In the assay for the NTDs of human MutL homologs, reactions were performed at $37^{\circ} \mathrm{C}$ for $120 \mathrm{~min}$. The reactions were stopped by the addition of $200 \mu \mathrm{L}$ of BIOMOL Green reagent (Enzo Life Sciences). Mixtures were incubated at room temperature for $30 \mathrm{~min}$ to allow the color development. The absorbance at $620 \mathrm{~nm}$ was measured by a microplate reader $680 \mathrm{XR}$ (Bio-Rad Laboratories). The experiments were performed in triplicate. The standard Michaelis-Menten equation was fitted to the data to determine the $k_{\text {cat }}$ and $K_{\mathrm{m}}$ values.

For the measurements of the ATPase activity of aqMutL under different $\mathrm{pH}$ conditions, reactions were performed at $60^{\circ} \mathrm{C}$, and in place of $50 \mathrm{mM}$ HEPES-KOH, $50 \mathrm{mM}$ sodium acetate, $50 \mathrm{mM}$ MES-NaOH, $50 \mathrm{mM}$ Tris- $\mathrm{HCl}$, or $50 \mathrm{mM}$ sodium carbonate/bicarbonate was used to cover the $\mathrm{pH}$ range from 3.5 to 5.5 , from 6.5 to 7.0 , from 7.5 to 9.0 , or from 9.2 to 10.7 , respectively. Measurements at $\mathrm{pH} 5.5,7.5$, and 9.0 were carried out with two kinds of buffering agents, sodium acetate or MES-KOH for $\mathrm{pH} 5.5$, MES-KOH or Tris- $\mathrm{HCl}$ for $\mathrm{pH} 7.5$, and Tris- 
$1 \mathrm{HCl}$ or sodium carbonate/bicarbonate for $\mathrm{pH}$ 9.0, which revealed that difference of the agents did

2 not affect the ATPase activity of aqMutL.

3 The $\mathrm{pH}$ profile of the aqMutL ATPase activity was analyzed as follows: In the presence of 4 saturating amounts of the substrate, all of the enzyme molecules in the reaction mixture are

5 essentially in the form of the enzyme-substrate complex (ES). Accordingly, the $\mathrm{pH}$ profile can

6 be analyzed by the simple scheme:

7

$$
\begin{gathered}
\text { ES } \\
K_{\mathrm{ES}} \downarrow \uparrow \\
\mathrm{HES} \stackrel{k_{\text {cat }}}{\rightarrow} \mathrm{HE}+\mathrm{P} \\
K_{\mathrm{HES}} \downarrow \uparrow \\
\mathrm{H}_{2} \mathrm{ES}
\end{gathered}
$$

where ES, HES, and $\mathrm{H}_{2} \mathrm{ES}$ are unprotonated, singly-protonated, and doubly-protonated ES,

11 respectively, and only HES is enzymatically active; $K_{\mathrm{ES}}$ and $K_{\mathrm{HES}}$ are the acid dissociation constants for the corresponding protonation/deprotonation steps. The $k_{\text {cat }}$ value at each $\mathrm{pH}$

$13\left(\left(k_{\mathrm{cat}}\right)_{\mathrm{H}}\right)$ is defined by

$\left(k_{\mathrm{cat}}\right)_{\mathrm{H}}=k_{\mathrm{cat}}[\mathrm{HES}] /[\mathrm{ES}]_{0} \quad($ equation 1$)$,

where $[\mathrm{ES}]_{0}$ is the total concentration of the enzyme-substrate complex and defined by $[\mathrm{ES}]_{0}=$

21 From these, 
$2[\mathrm{ES}]_{0}=[\mathrm{HES}]\left(\left[\mathrm{H}^{+}\right] / K_{\mathrm{HES}}+1+K_{\mathrm{ES}} /\left[\mathrm{H}^{+}\right]\right)$, and

3

$4 \quad[\mathrm{HES}] /[\mathrm{ES}]_{0}=1 /\left(\left[\mathrm{H}^{+}\right] / K_{\mathrm{HES}}+1+K_{\mathrm{ES}} /\left[\mathrm{H}^{+}\right]\right) \quad$ (equation 2$)$.

5

6 By substituting the equation 2 for $[\mathrm{HES}] /[\mathrm{ES}]_{0}$ in the equation 1 , the $\mathrm{pH}$ dependence of $k_{\text {cat }}$ is 7 obtained:

8

$9 \log \left(k_{\mathrm{cat}}\right)_{\mathrm{H}}=\log k_{\mathrm{cat}}-\log \left[\left(\left[\mathrm{H}^{+}\right] / K_{\mathrm{HES}}\right)+1+\left(K_{\mathrm{ES}} /\left[\mathrm{H}^{+}\right]\right)\right] \quad$ (equation 3$)$.

$\mathrm{p} K_{\mathrm{HES}}$ and $\mathrm{p} K_{\mathrm{ES}}$ values were obtained by fitting the equation 3 to the data using Igor Pro 8.

Complementation experiment.

The mutL-lacking T. thermophilus HB8 strain was constructed as previously described (47). The wildtype, R27E, K78A, K78R, and K291A T. thermophilus mutL genes were ligated into the pMK18::Hyg $\Delta$ Kan plasmid $(54,55)$ using XbaI and HindIII restriction sites. These plasmids were then transformed into the mutL-lacking $T$. thermophilus HB8 strain. The frequency of streptomycin-resistant cells of the transformants were measured by the previously described method (47).

T. thermophilus HB8 cells at the late-exponential growth phase were harvested by centrifugation

24 and suspended in a buffer containing $50 \mathrm{mM}$ Tris- $\mathrm{HCl}(\mathrm{pH} 8.0), 100 \mathrm{mM} \mathrm{NaCl}, 10 \%$ glycerol. 
1 The cells were lysed by ultrasonication on ice. After centrifugation, total protein concentrations

2 in the supernatants were determined by Bradford method. Ten $\mu \mathrm{g}$ total protein of each sample

3 was subjected to SDS-PAGE (10\% polyacrylamide gel) and electroblotted onto a nitrocellurose

4 membrane. The membrane was incubated in a blocking solution comprising $20 \mathrm{mM}$ Tris-HCl

5 (pH 7.5), $500 \mathrm{mM} \mathrm{NaCl}$, and 3\% bovine serum albumin (nacalai) for $30 \mathrm{~min}$ at room temperature.

6 After washing with the washing solution comprising $20 \mathrm{mM}$ Tris- $\mathrm{HCl}(\mathrm{pH} 7.5), 500 \mathrm{mM} \mathrm{NaCl}$,

7 and $0.05 \%$ Tween-20 (nacalai), the membrane was immersed into the blocking solution

8 containing rabbit anti-T. thermophilus MutL or anti-T. thermophilus MutS2 antiserum and

9 incubated for $1 \mathrm{~h}$ at room temperature. The membrane was washed with the washing solution and then, reacted with Protein A-horseradish peroxidase conjugate (Bio-Rad Laboratories) in the blocking solution for $2 \mathrm{~h}$ at room temperature. The membrane was washed with the washing solution twice and then reacted with 4-chloro-1-naphthol (Bio-Rad Laboratories) in the HRP color development buffer (Bio-Rad Laboratories) for $10 \mathrm{~min}$ at room temperature. The staining was stopped by washing the membrane in deionized water.

Limited proteolysis.

17 The wildtype and mutant forms of the aqMutL NTD $(5 \mu \mathrm{M})$ were reacted with $30 \mathrm{ng} / \mu \mathrm{l}$ trypsin

18 (from bovine pancreas; Sigma Aldrich) in a buffer consisting of $50 \mathrm{mM}$ Tris- $\mathrm{HCl}$ (pH 8.0), 100 $\mathrm{mM} \mathrm{NaCl}, 5 \mathrm{mM} \mathrm{MgCl}$, and $0,0.25$ or $0.5 \mathrm{mM} \mathrm{AMPPNP}$ at $37^{\circ} \mathrm{C}$ for $20 \mathrm{~min}$. Reactions were stopped by addition of an equal volume of the SDS-containing dye comprised of $125 \mathrm{mM}$ Tris$\mathrm{HCl}(\mathrm{pH} 7.5$ ), 10\% 2-mercaptoethanol, 4\% SDS, 10\% sucrose, and $0.01 \%$ bromophenol blue. 
Equilibrium dialysis.

2 Seventy five microliter of $50 \mathrm{mM}$ Tris- $\mathrm{HCl}(\mathrm{pH} 8.0), 100 \mathrm{mM} \mathrm{NaCl}$, and $5 \mathrm{mM} \mathrm{MgCl}_{2}$ containing

$350 \mu \mathrm{M}$ AMPPNP was loaded into the buffer chamber of the DispoEquilibrium Dialyzer (10 kDa

4 molecular weight cut off membrane) (Harvard Bioscience, Inc.). Subsequently, an equivalent

5 volume of the aqMutL NTD $(0-320 \mu \mathrm{M})$ in $50 \mathrm{mM}$ Tris- $\mathrm{HCl}(\mathrm{pH} 8.0), 100 \mathrm{mM} \mathrm{NaCl}$, and $5 \mathrm{mM}$

$6 \quad \mathrm{MgCl}_{2}$ was placed into the opposite sample chamber of the device. The device was gently agitated

7 on a shaker at room temperature for $16 \mathrm{~h}$. The absorbance at $260 \mathrm{~nm}$ of the solution from the

8 buffer chamber was measured. The concentration of unbound AMPPNP was calculated by using

9 a molar extinction coefficient, $15,400 \mathrm{M}^{-1} \mathrm{~cm}^{-1}$. The following equation was fitted to the data to determine $K_{\mathrm{d}}$ values of the wildtype and K79A aqMutL NTDs.

$[$ Bound AMPPNP $]=\left\{K_{\mathrm{d}}+[\text { aqMutL NTD }]_{0}+[\text { AMPPNP }]_{0}-\left[\left(K_{\mathrm{d}}+[\text { aqMutL NTD }]_{0}+\right.\right.\right.$ $\left.\left.\left.[\mathrm{AMPPNP}]_{0}\right)^{2}-4[\mathrm{aqMutL} \mathrm{NTD}]_{0}[\mathrm{AMPPNP}]_{0}\right]^{1 / 2}\right\} / 2 \quad$ (equation 4$)$, respectively.

\section{Data Availability}


1 This work was supported by JSPS KAKENHI grant number JP19K07376 (to KF). Authors

2 thank Prof. Ryoji Masui (Osaka City University) for providing the pMK18::Hyg $\Delta$ Kan plasmid.

3

\section{Author contributions}

\section{Conflict of interest}

The authors declare that they have no conflict of interest.

K.F and T.Y conceptualized the project. K.F. performed all experiments. Y.F. constructed the18::Hyg $\Delta$ Kan plasmid. K.F. and T.Y. analyzed the data and wrote the manuscript with help from Y.F.

1. Iyer, R. R., Pluciennik, A., Burdett, V., and Modrich, P. L. (2006) DNA mismatch repair: functions and mechanisms. Chem Rev 106, 302-323

2. Modrich, P. (2006) Mechanisms in eukaryotic mismatch repair. J Biol Chem 281, 30305-30309

3. Fishel, R. (2015) Mismatch Repair. J Biol Chem 290, 26395-26403

4. Tham, K. C., Kanaar, R., and Lebbink, J. H. G. (2016) Mismatch repair and homeologous recombination. DNA Repair (Amst) 38, 75-83

5. Friedhoff, P., Li, P., and Gotthardt, J. (2016) Protein-protein interactions in DNA mismatch repair. DNA Repair (Amst) 38, 50-57

6. Groothuizen, F. S., Winkler, I., Cristovao, M., Fish, A., Winterwerp, H. H., Reumer, A., Marx, A. 
7. Kadyrov, F. A., Dzantiev, L., Constantin, N., and Modrich, P. (2006) Endonucleolytic function of

8. Kadyrov, F. A., Holmes, S. F., Arana, M. E., Lukianova, O. A., O'Donnell, M., Kunkel, T. A., and Modrich, P. (2007) Saccharomyces cerevisiae MutLa is a mismatch repair endonuclease. J Biol Chem 282, 37181-37190

9. Kadyrova, L. Y., and Kadyrov, F. A. (2015) Endonuclease activities of MutLalpha and its homologs in DNA mismatch repair. DNA Repair (Amst)

10. Jiricny, J., and Nystrom-Lahti, M. (2000) Mismatch repair defects in cancer. Curr Opin Genet Dev

11. Fishel, R., and Kolodner, R. D. (1995) Identification of mismatch repair genes and their role in

12. Fishel, R., Lescoe, M. K., Rao, M. R., Copeland, N. G., Jenkins, N. A., Garber, J., Kane, M., and

13. Stojic, L., Brun, R., and Jiricny, J. (2004) Mismatch repair and DNA damage signalling. DNA Repair (Amst) 3, 1091-1101

14. Drummond, J. T., Anthoney, A., Brown, R., and Modrich, P. (1996) Cisplatin and adriamycin resistance are associated with MutLalpha and mismatch repair deficiency in an ovarian tumor cell line. J Biol Chem 271, 19645-19648 
resistance to cisplatin. Cancer Res 56, 3087-3090

16. Fink, D., Aebi, S., and Howell, S. B. (1998) The role of DNA mismatch repair in drug resistance. Clin Cancer Res 4, 1-6

17. Koi, M., Umar, A., Chauhan, D. P., Cherian, S. P., Carethers, J. M., Kunkel, T. A., and Boland, C. R. (1994) Human chromosome 3 corrects mismatch repair deficiency and microsatellite instability and reduces N-methyl-N'-nitro-N-nitrosoguanidine tolerance in colon tumor cells with homozygous hMLH1 mutation. Cancer Res 54, 4308-4312

18. Le, D. T., Uram, J. N., Wang, H., Bartlett, B. R., Kemberling, H., Eyring, A. D., Skora, A. D., Luber, B. S., Azad, N. S., Laheru, D., Biedrzycki, B., Donehower, R. C., Zaheer, A., Fisher, G. A., Crocenzi, T. S., Lee, J. J., Duffy, S. M., Goldberg, R. M., de la Chapelle, A., Koshiji, M., Bhaijee, F., Huebner, T., Hruban, R. H., Wood, L. D., Cuka, N., Pardoll, D. M., Papadopoulos, N., Kinzler, K. W., Zhou, S., Cornish, T. C., Taube, J. M., Anders, R. A., Eshleman, J. R., Vogelstein, B., and Diaz, L. A., Jr. (2015) PD-1 Blockade in Tumors with Mismatch-Repair Deficiency. $N$ Engl J Med 372, 2509-2520

19. Le, D. T., Durham, J. N., Smith, K. N., Wang, H., Bartlett, B. R., Aulakh, L. K., Lu, S., Kemberling, H., Wilt, C., Luber, B. S., Wong, F., Azad, N. S., Rucki, A. A., Laheru, D., Donehower, R., Zaheer, A., Fisher, G. A., Crocenzi, T. S., Lee, J. J., Greten, T. F., Duffy, A. G., Ciombor, K. K., Eyring, A. D., Lam, B. H., Joe, A., Kang, S. P., Holdhoff, M., Danilova, L., Cope, L., Meyer, C., Zhou, S., Goldberg, R. M., Armstrong, D. K., Bever, K. M., Fader, A. N., Taube, J., Housseau, F., Spetzler, D., Xiao, N., Pardoll, D. M., Papadopoulos, N., Kinzler, K. W., Eshleman, J. R., Vogelstein, B., Anders, R. A., and Diaz, L. A., Jr. (2017) Mismatch repair deficiency predicts response of solid tumors to PD-1 blockade. Science 357, 409-413

20. Mandal, R., Samstein, R. M., Lee, K. W., Havel, J. J., Wang, H., Krishna, C., Sabio, E. Y., Makarov, V., Kuo, F., Blecua, P., Ramaswamy, A. T., Durham, J. N., Bartlett, B., Ma, X., 
Srivastava, R., Middha, S., Zehir, A., Hechtman, J. F., Morris, L. G., Weinhold, N., Riaz, N., Le, D. T., Diaz, L. A., Jr., and Chan, T. A. (2019) Genetic diversity of tumors with mismatch repair deficiency influences anti-PD-1 immunotherapy response. Science 364, 485-491

21. Hofstra, R. M., Spurdle, A. B., Eccles, D., Foulkes, W. D., de Wind, N., Hoogerbrugge, N., and Hogervorst, F. B. (2008) Tumor characteristics as an analytic tool for classifying genetic variants of uncertain clinical significance. Hum Mutat 29, 1292-1303

22. Dutta, R., and Inouye, M. (2000) GHKL, an emergent ATPase/kinase superfamily. Trends Biochem Sci 25, 24-28

23. Ban, C., Junop, M., and Yang, W. (1999) Transformation of MutL by ATP binding and hydrolysis: a switch in DNA mismatch repair. Cell 97, 85-97

24. Bergerat, A., de Massy, B., Gadelle, D., Varoutas, P. C., Nicolas, A., and Forterre, P. (1997) An atypical topoisomerase II from Archaea with implications for meiotic recombination. Nature 386, 414-417

25. Thompson, J. D., Gibson, T. J., and Higgins, D. G. (2002) Multiple sequence alignment using ClustalW and ClustalX. Curr Protoc Bioinformatics Chapter 2, Unit 23

26. Robert, X., and Gouet, P. (2014) Deciphering key features in protein structures with the new ENDscript server. Nucleic Acids Res 42, W320-324

27. Sacho, E. J., Kadyrov, F. A., Modrich, P., Kunkel, T. A., and Erie, D. A. (2008) Direct visualization of asymmetric adenine-nucleotide-induced conformational changes in MutLa. Mol Cell 29, 112-121

28. Yamamoto, T., Iino, H., Kim, K., Kuramitsu, S., and Fukui, K. (2011) Evidence for ATPdependent structural rearrangement of nuclease catalytic site in DNA mismatch repair endonuclease MutL. J Biol Chem 286, 42337-42348

29. Mauris, J., and Evans, T. C. (2009) Adenosine triphosphate stimulates Aquifex aeolicus MutL 
endonuclease activity. PLoS One 4, e7175

30. Spampinato, C., and Modrich, P. (2000) The MutL ATPase is required for mismatch repair. J Biol Chem 275, 9863-9869

31. Tomer, G., Buermeyer, A. B., Nguyen, M. M., and Liskay, R. M. (2002) Contribution of human mlh1 and pms2 ATPase activities to DNA mismatch repair. J Biol Chem 277, 21801-21809

32. Hall, M. C., Shcherbakova, P. V., and Kunkel, T. A. (2002) Differential ATP binding and intrinsic ATP hydrolysis by amino-terminal domains of the yeast Mlh1 and Pms1 proteins. J Biol Chem 277, 3673-3679

33. Guarne, A., Junop, M. S., and Yang, W. (2001) Structure and function of the N-terminal $40 \mathrm{kDa}$ fragment of human PMS2: a monomeric GHL ATPase. EMBO J 20, 5521-5531

34. Ban, C., and Yang, W. (1998) Crystal structure and ATPase activity of MutL: implications for DNA repair and mutagenesis. Cell 95, 541-552

35. Fukui, K., Iino, H., Baba, S., Kumasaka, T., Kuramitsu, S., and Yano, T. (2017) Crystal structure and DNA-binding property of the ATPase domain of bacterial mismatch repair endonuclease MutL from Aquifex aeolicus. Biochim Biophys Acta 1865, 1178-1187

36. Izuhara, K., Fukui, K., Murakawa, T., Baba, S., Kumasaka, T., Uchiyama, K., and Yano, T. (2020) A Lynch syndrome-associated mutation at a Bergerat ATP-binding fold destabilizes the structure of the DNA mismatch repair endonuclease MutL. J Biol Chem 295, 11643-11655

37. Wu, H., Zeng, H., Lam, R., Tempel, W., Kerr, I. D., and Min, J. (2015) Structure of the human MLH1 N-terminus: implications for predisposition to Lynch syndrome. Acta Crystallogr F Struct Biol Commun 71, 981-985

38. Arana, M. E., Holmes, S. F., Fortune, J. M., Moon, A. F., Pedersen, L. C., and Kunkel, T. A. (2010) Functional residues on the surface of the N-terminal domain of yeast Pms1. DNA Repair (Amst) 9, 448-457 
1 39. Deckert, G., Warren, P. V., Gaasterland, T., Young, W. G., Lenox, A. L., Graham, D. E., Overbeek, R., Snead, M. A., Keller, M., Aujay, M., Huber, R., Feldman, R. A., Short, J. M., Olsen, G. J., and Swanson, R. V. (1998) The complete genome of the hyperthermophilic bacterium Aquifex aeolicus. Nature 392, 353-358

40. Fukui, K., Kosaka, H., Kuramitsu, S., and Masui, R. (2007) Nuclease activity of the MutS homologue MutS2 from Thermus thermophilus is confined to the Smr domain. Nucleic Acids Res 35, $850-860$

41. Iwai, T., Kuramitsu, S., and Masui, R. (2004) The Nudix hydrolase Ndx1 from Thermus thermophilus HB8 is a diadenosine hexaphosphate hydrolase with a novel activity. J Biol Chem 279, 21732-21739

42. Kiefer, F., Arnold, K., Kunzli, M., Bordoli, L., and Schwede, T. (2009) The SWISS-MODEL Repository and associated resources. Nucleic Acids Res 37, D387-392

43. Junop, M. S., Yang, W., Funchain, P., Clendenin, W., and Miller, J. H. (2003) In vitro and in vivo studies of MutS, MutL and MutH mutants: correlation of mismatch repair and DNA recombination. DNA Repair (Amst) 2, 387-405

44. Bolz, N. J., Lenhart, J. S., Weindorf, S. C., and Simmons, L. A. (2012) Residues in the N-terminal domain of MutL required for mismatch repair in Bacillus subtilis. J Bacteriol 194, 5361-5367

45. Raevaara, T. E., Korhonen, M. K., Lohi, H., Hampel, H., Lynch, E., Lonnqvist, K. E., HolinskiFeder, E., Sutter, C., McKinnon, W., Duraisamy, S., Gerdes, A. M., Peltomaki, P., KohonenCcorish, M., Mangold, E., Macrae, F., Greenblatt, M., de la Chapelle, A., and Nystrom, M. (2005) Functional significance and clinical phenotype of nontruncating mismatch repair variants of MLH1. Gastroenterology 129, 537-549

46. Morita, R., Nakane, S., Shimada, A., Inoue, M., Iino, H., Wakamatsu, T., Fukui, K., Nakagawa, N., Masui, R., and Kuramitsu, S. (2010) Molecular mechanisms of the whole DNA repair system: 
24 47. Fukui, K., Nishida, M., Nakagawa, N., Masui, R., and Kuramitsu, S. (2008) Bound nucleotide

48. Shimada, A., Kawasoe, Y., Hata, Y., Takahashi, T. S., Masui, R., Kuramitsu, S., and Fukui, K.

6 (2013) MutS stimulates the endonuclease activity of MutL in an ATP-hydrolysis-dependent manner. FEBS J 280, 3467-3479

49. Agrawal, A., Roue, M., Spitzfaden, C., Petrella, S., Aubry, A., Hann, M., Bax, B., and Mayer, C. (2013) Mycobacterium tuberculosis DNA gyrase ATPase domain structures suggest a dissociative mechanism that explains how ATP hydrolysis is coupled to domain motion. Biochem J 456, 263273

50. Jackson, A. P., and Maxwell, A. (1993) Identifying the catalytic residue of the ATPase reaction of DNA gyrase. Proc Natl Acad Sci U S A 90, 11232-11236

51. O'Dea, M. H., Tamura, J. K., and Gellert, M. (1996) Mutations in the B subunit of Escherichia coli DNA gyrase that affect ATP-dependent reactions. J Biol Chem 271, 9723-9729

52. Gross, C. H., Parsons, J. D., Grossman, T. H., Charifson, P. S., Bellon, S., Jernee, J., Dwyer, M., Chambers, S. P., Markland, W., Botfield, M., and Raybuck, S. A. (2003) Active-site residues of Escherichia coli DNA gyrase required in coupling ATP hydrolysis to DNA supercoiling and amino acid substitutions leading to novobiocin resistance. Antimicrob Agents Chemother 47, 1037-1046

53. Ishii, S., Yano, T., Okamoto, A., Murakawa, T., and Hayashi, H. (2013) Boundary of the nucleotide-binding domain of Streptococcus ComA based on functional and structural analysis. Biochemistry 52, 2545-2555

54. Inoue, M., Fukui, K., Fujii, Y., Nakagawa, N., Yano, T., Kuramitsu, S., and Masui, R. (2017) The Lon protease-like domain in the bacterial RecA paralog RadA is required for DNA binding and 
bioRxiv preprint doi: https://doi.org/10.1101/2021.07.09.451751; this version posted July 10, 2021. The copyright holder for this preprint

(which was not certified by peer review) is the author/funder, who has granted bioRxiv a license to display the preprint in perpetuity. It is made available under aCC-BY 4.0 International license. 